CIRJE-F-1129

\title{
Intergovernmental Competition for Donations : The Case of the Furusato Nozei Program in Japan
}

\author{
Eiji Fukasawa \\ National Diet Library \\ Takeshi Fukasawa \\ Graduate School of Economics, The University of Tokyo \\ Hikaru Ogawa \\ The University of Tokyo
}

October 2019

\begin{abstract}
CIRJE Discussion Papers can be downloaded without charge from:
http://www.cirje.e.u-tokyo.ac.jp/research/03research02dp.html
\end{abstract}

Discussion Papers are a series of manuscripts in their draft form. They are not intended for circulation or distribution except as indicated by the author. For that reason Discussion Papers may not be reproduced or distributed without the written consent of the author. 


\title{
Intergovernmental competition for donations : The case of the Furusato Nozei program in Japan
}

\author{
Eiji Fukasawa \\ National Diet Library \\ 1-10-1, Nagatacho, Chiyoda-ku, Tokyo, 100-8924, Japan \\ e-fukasa@ndl.go.jp \\ Takeshi Fukasawa \\ The University of Tokyo \\ 7-3-1, Hongo, Bunkyo-ku, Tokyo, 113-0033, Japan \\ fukasawa3431@gmail.com \\ Hikaru Ogawa \\ The University of Tokyo \\ 7-3-1, Hongo, Bunkyo-ku, Tokyo, 113-0033, Japan \\ ogawa@e.u-tokyo.ac.jp
}

\begin{abstract}
This paper shows that municipalities compete excessively for donations under a unique program called Furusato Nozei (Tax payment to hometown) in Japan. Under the program, people make donations to their favorite municipalities and municipalities that have received donations give "reciprocal" gifts in return. Our estimates show that municipalities facing competition to attract donations provide excessive gifts to donors, and net revenue from the program is $10.4 \%$ to $12.1 \%$ lower than in a scenario without competition.
\end{abstract}

JEL Classification. H77, R28, R51.

Keywords. Interregional fiscal competition, donation, efficiency. 


\section{Introduction}

The Japanese government launched a new program called Furusato Nozei (Tax payment to hometown) in 2008, in which an individual makes a charitable donation to municipalities that they believe have been helped in the past. These donations can be regarded as ordinary tax revenues collected by municipal governments. Donors paying income tax in their region of residence receive an income tax deduction approximately equal to the amount donated. That is, individuals can allocate a proportion of their income tax payments to any of their favorite municipalities. In addition to tax credits, under this program, donors also benefit by receiving the "reciprocal" or "thank you" gifts from the donating municipality. Typical gifts include local products and specialties, which can either be consumed or resold. This study focuses on such pecuniary benefits offered by municipalities and quantitatively evaluates the Furusato Nozei program, based on tax and fiscal competition theory (Zodrow and Miezskowski, 1986; Wilson, 1986; Wildasin, 1988).

The fact that municipalities can send "reciprocal" gifts to donors implies the inevitable generation of competition among municipal governments in the acquisition of donations via the "return rate" - the percentage of gifts' value returned to the donation received. ${ }^{1}$ In fact, in addition to local specialties, municipalities also gifted items such as an iPad, Apple Watch, Amazon gift card, and e-money to interest donors. Specifically, it has been pointed out that due to intense intergovernmental competition in a bid to attract donations, municipalities engage in wasteful competition. There are municipalities with negative fiscal balances because of the Furusato Nozei program (Suzuki and Hashimoto, 2017). This is a typical negative aspect of so-called fiscal competition, which results in excessive competition among municipalities. Faced with these situations, the central government in 2017 issued a notice to ease competition. However, since this notification did not impose penalties, many municipal governments did not abide by it. In 2019, the central government finally revised the local tax law and decided to exclude from this program municipalities that offer excessive "reciprocal" gifts. Accordingly, four municipalities were identified and excluded. However, the regulation of intergovernmental competition is just beginning, and a solid framework is yet to be established.

The main purpose of this study is to construct a simple model of the Furusato Nozei program, and thereby elucidate quantitatively the inefficient loss in revenue that accompanies excessive intergovernmental competition for donations under the program. Because only two years of data on donations are available, it is difficult to conduct a long-run panel data analysis. However, for all 1,741 municipalities including 23 special wards of Tokyo, we construct a panel data set for the available time periods and quantify the competition for donations among municipal governments.

The findings of our paper indicate that there is excessive competition among municipalities that participate in the program in the sense that the absence of competition between municipalities results in higher net revenues. Specifically, our quantitative analysis depicts the following empirical findings: Firstly, a municipality raises its return rate to the extent of 2.5 to $4.1 \%$ points, if other municipalities raise their return rates to donations by $10 \%$ points. In cases where the actual data can be reproduced the most, these values range from 2.5 to $2.7 \%$ points. Secondly, in comparison to a hypothetical scenario with no competition, competition among municipalities raises donations by $22.5 \%$ to $24.9 \%$. Thirdly, due to intergovernmental competition through rising return rates for donations, the extent of the decline in net revenue ranges from $10.4 \%$ to $12.1 \%$ in comparison to a scenario without competition. This is because the cost

\footnotetext{
${ }^{1}$ Suppose an individual donated $¥ 150,000$ to Yukuhashi, a typical local city with a population of 70,000 . In return, she receives an income tax deduction of $¥ 148,000$ from the government of the municipality in which she resides. In addition, she receives a $32 \mathrm{~GB}$ iPad with Wi-Fi as a "reciprocal" gift from Yukuhashi city. Since the price of the item is $¥ 63,800$, the return rate in this case is calculated as $42.5 \%(=63,800 / 150,000)$.
} 
of procuring gifts for collected donations increases by raising return rates. These results imply that municipalities engage in excessive competition for attracting donations, and thus support the central government's policy of restricting the upper limit of the return rate.

The remainder of the paper is organized as follows. In section 2 , we briefly introduce the Furusato Nozei program. In section 3, we set up the basic model that characterizes the program. In section 4, we explain the data and empirically test the model. Based on the estimation results, we quantitatively depict a distortion in non-cooperative competition for donations among municipalities. Section 5 concludes the paper.

\section{The Furusato Nozei program}

\subsection{Description of the program}

In this subsection, we briefly describe the essence of the program. ${ }^{2}$ Under this program, individuals donate to municipalities where they feel they have been helped in the past. A typical example is the region where they were born and raised. In addition, they can designate the places where their parents or partner came from or places they visited for sightseeing as the places where they indebted to. In fact, people can donate to any municipality that they regard as their hometown. When people donate to a certain municipality, their income tax to be paid to the government of the municipality where they reside is deducted. This is explained in detail later with an example.

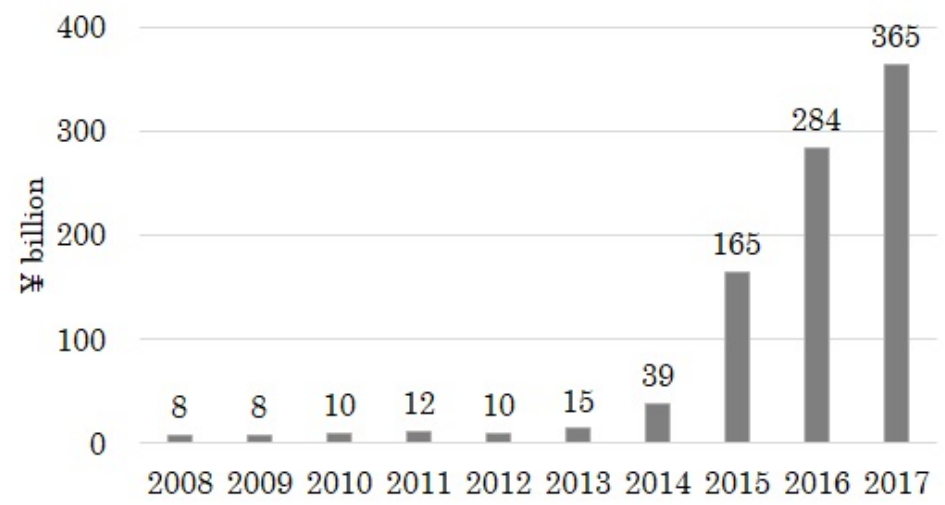

Figure 1 Changes in donation

The Furusato Nozei program began in 2008, but initially, it did not induce many donations. The reasons for few donations in the beginning are as follows: Firstly, unlike today, it was purely a donation program, with no municipality providing a "reciprocal" gift. Secondly, the procedure for donations and tax deductions was complicated, and the transaction costs incurred for making donations were high. Since the mid-2010s, the number and amount of donations have greatly increased (see Figure 1). This is due to, first, the doubling of the income tax credit limit in 2015, which in turn, raised the incentive to make donations with tax-related motives. Second, municipalities have begun competing for donations by offering "reciprocal" gifts in return, which is the focal point of the paper. Apart from gifts that typically include local specialties such as rice, beef and seafood, other kinds of goods such as electrical appliances, e-money, gift cards, hotel accommodation tickets, and air tickets have been provided to attract donations. Third, a system that eliminates the need for tax returns was in place, which simplified the tax deductions process. At the same time, private firms set up a portal site on the internet for this program.

\footnotetext{
${ }^{2}$ See also Japan Times (2017) and Rausch (2017) for more details about of the program.
} 
Table 1: Donation and tax deduction $(¥ 1,000)$

\begin{tabular}{l|rrr}
\hline \hline Annual taxable income & 5000.0 & 5000.0 & \\
\hline National tax payment & 572.5 & 560.9 & $\mathbf{\Delta} 11.6$ \\
Local tax payment & 500.0 & 453.6 & $\mathbf{\Delta} 46.4$ \\
Donation & 0.0 & 60.0 & 60.0 \\
\hline Consumption & 3927.5 & 3925.5 & $\mathbf{\Delta} 2.0$ \\
\hline Gifts received & 0.0 & 25.2 & 25.2 \\
Total consumption & 3927.5 & 3950.7 & 23.2 \\
\hline \hline
\end{tabular}

Note. This is an example of a household with an annual taxable income of $¥ 5,000$ thousand. The rightmost column shows the difference between the values with and without a donation.

The launch of the website helped match municipalities to donors and lowered transaction costs by facilitating credit card payments.

Based on Table 1, we explain the workings of Furusato Nozei program. Assume that an individual earns an annual taxable income of $¥ 5,000$ thousand. He pays $¥ 572.5$ thousand as income tax to the national government and $¥ 500.0$ thousand to the governments of the municipality in which he resides. If he does not donate to any municipality, the amount of money remaining in hand for consumption is $¥ 3927.5$ thousand. There is a limit on the amount that can be donated, depending upon the taxable income. For example, a single individual (or a working couple with no children) with an annual taxable income of $¥ 5,000$ thousand can donate up to about $¥ 60,000$ under this program. So, assume that an individual donates the upper limit of $¥ 60,000$ to some municipality. In this case, tax payments to the national and municipal governments are reduced to $¥ 560.9$ thousand and $¥ 453.6$ thousand, respectively. Therefore, the amount of money remaining in hand is $¥ 3,925.5$ thousand. Instead of losing $¥ 2,000(=3,927.5-3,925.5)$, he receives gifts worth $¥ 25,200$, which is approximately $42 \%$ of the donation. ${ }^{3}$ Thus, the amount he can ultimately utilize for personal consumption will be $¥ 3,950.7$ thousand, an increase of $0.6 \%$ in comparison to the amount in hand prior to making the donation, $¥ 3927.5$ thousand. If " $0.6 \%$ " is referred to as the yield in terms of the donation, this will be larger for higher income earners. For example, if a single individual with an annual taxable income of $¥ 18,000$ thousand donates $¥ 500,000$, which is the maximum that can be donated, it is about $1.8 \%$. High-income earners can hence claim more benefits under this program, an aspect that has been criticized and deemed as one of its disadvantages (Bessho, 2017).

Table 2 depicts the impact on the fiscal balances of municipalities when an individual donates $¥ 60,000$ to some municipality. If an individual donates $¥ 60,000$, he receives a gift worth $¥ 25,200$, which is equivalent to $42 \%$ of the donation, from the concerned municipality. When he donates $¥ 60,000$, the tax credit that he receives is $¥ 58,000$, implying that he loses $¥ 2,000$. The difference between the value of the gift, $¥ 25,200$, and the loss of $¥ 2,000$ constitutes the individual’s net benefit from the donation. For the municipality where the individual who donated $¥ 60,000$ resides, this implies a decline in tax revenue to the tune of $¥ 46,400$ (see the third row in Table 1). However, $75 \%$ of them are covered by transfers from the central government, meaning that the net loss of revenue is $¥ 11,600$, or $25 \%$ of the $¥ 46,400$. The municipality that receives the donation of $¥ 60,000$ sends a gift worth $42 \%$ of the donation amount. Hence, the increase in net revenue is $¥ 34,800$. As we can see from the second row of Table 1, the central government loses $¥ 11,600$ due to tax deductions. In addition, since it covers $75 \%$ of the loss in tax revenue for municipalities that participate in the program, the balance will be $¥ 46,400(11,600+34,800)$ minus.

As seen from Table 2, this program redistributes tax revenues among municipalities. Since

\footnotetext{
${ }^{3}$ The figure of $42 \%$ is an illustration in the context of the city of Yukuhashi introduced in footnote 1.
} 
Table 2: Benefit and burden $(¥ 1,000)$

\begin{tabular}{l|rrr}
\hline \hline & Revenue increase & Revenue loss & Net revenue \\
\hline Donor & 25.2 & 2.0 & 23.2 \\
Municipality the donor lives & 34.8 & 46.4 & $\mathbf{\Delta} 11.6$ \\
Municipality that received the donation & 60.0 & 25.2 & 34.8 \\
Central government & 0.0 & 46.4 & $\boldsymbol{\Delta} 46.4$ \\
\hline Total & 120.0 & 120.0 & 0 \\
\hline \hline
\end{tabular}

Note. A case example when a donation of $¥ 60,000$ is made.

it is common for individuals to donate to municipalities other than those in which they reside, the net revenue tends to be negative in the case of municipalities especially in the urban areas, where there are a large number of residents having incentives to receive tax deductions due to high income.

\subsection{Literature review}

Research interest in this program is fairly recent. Although there are few studies that have analyzed the program, four are noteworthy.

Hashimoto and Suzuki (2016) analyzed the correlation (not causality) between the donations that municipalities receive and the fiscal conditions of those municipalities. Their results depict a weak but positive correlation between donations and population size. However, there is no evidence to suggest that the donations that municipalities receive and the index of the fiscal conditions of municipalities are related. Yamamura et al. (2018) revealed that the amount of donations received by municipalities changed after the occurrence of a large-scale natural disaster. This demonstrated that the motivation for making donations may have become more altruistic. They also estimated the elasticity of donations with respect to the return rate, and revealed that the donations made to municipalities increase by $0.61 \%$ if municipalities increase their spending on "reciprocal" gifts by $1 \%$. Based on the results of an original survey, Nishimura et al. (2017) analyzed the motivation for making donations by dividing the motive into two categories. First, the donations to those municipalities characterized by weak financial conditions, a reliance on the agricultural sector, and high unemployment rates, are regarded as donations based on altruistic intentions. Second, donations to those municipalities that provide a large number of reciprocal gifts and high rates of return are regarded as donations based on selfish intentions. Their estimation results indicate that donations made under the Furusato Nozei program are generally governed by selfish intentions. Fukasawa (2019) conducted a single regression, using data from 791 cities in 2017, to ascertain whether the return rate for donations for a specific municipality depends on that of other rival municipalities. His findings indicated that when the return rate increased by $1 \%$, rival municipalities increase their rate of return to donations by $0.24 \%$ to $0.33 \%$.

All the above studies analyze the positive aspects of the program, but they do not provide a theoretical model that forms the basis of the analysis. The normative analysis of the current program is hence neglected. This study carries out a normative evaluation on the interregional competition for donations using the return rate to donations as a strategic policy instrument. Regarding this aspect, as depicted in the next section, we develop a simple model of donations in the context of tax competition framework. This is utilized in the estimation of the reaction functions of municipalities that participate in the Furusato Nozei program. 


\section{Model}

\section{$3.1 \quad$ Non-cooperative equilibrium}

Donors. There are symmetric $n(>1)$ municipalities competing for Furusato Nozei, which is essentially a donation made by individuals. In the program, individuals can reduce their income tax payments in accordance with their donations. To analyze an individual's decision on donation, we assume that the utility function of a representative donor is given by:

$$
U=x_{0}+u\left(x_{1}, . ., x_{n}\right),
$$

where

$$
u\left(x_{1}, . ., x_{n}\right) \equiv a \sum_{i=1}^{n} x_{i}-\frac{c}{2}\left[\sum_{i=1}^{n} x_{i}^{2}+2 b \sum_{i=1}^{n}\left(x_{i} \cdot \sum_{j=i+1}^{n} x_{j}\right)\right] .
$$

$x_{0}$ is the numeraire private goods and $x_{i}$ is the donation to municipality $i$. a represents the magnitude of the benefit from making a donation to a certain municipality, regardless of income tax deductions or gifts received. The substitutability of the donations between any two municipalities is measured by $b \in(0,1)$, where the donations to different municipalities are perfectly substitutable for $b \rightarrow 1$. For linear regression in the next section, the form of utility function has a nice feature of providing a linear demand function and a linear response function.

Let us set up an individual's budget constraint that explains the two benefits that the individual receives under the program. Assume that the income tax rate for individuals with income $y$ is $t \in(0,1)$, and that this individual donated $x_{i}$ to municipality $i$. Under the Furusato Nozei program, the amount obtained by subtracting $¥ 2,000$ from total donation is subject to a tax deduction. Therefore, when donating to $n$ municipalities, the total donation is $\sum_{i=1}^{n} x_{i}$, and the remainder after deducting $¥ 2,000$ will be subject to a tax deduction. This is the first benefit that donors receive under the program. The second benefit is provided by the municipal governments. When an individual donates $x_{i}$ to municipality $i$, he/she receives "reciprocal" gifts equivalent to $p_{i} x_{i}$ from municipal government $i$. Here, $p_{i} \in[0,1]$ is called the return rate, which is determined by each municipal government. In 2017, the central government has issued guidelines to make $p_{i}$ lower than 0.3. However, since it does not involve strong penalties, in fact, there are many municipalities that set the value to more than 0.3 . The budget constraint in terms of the individual earning income $y$ is given by:

$$
y-\left[t y-\left(\sum_{i=1}^{n} x_{i}-2,000\right)\right]+\sum_{i=1}^{n} p_{i} x_{i}=x_{0}+\sum_{i=1}^{n} x_{i} .
$$

The angle bracket in the second term on the left-hand side represents the tax payment after applying a tax deduction to the donation. If an individual donates $\sum_{i=1}^{n} x_{i}$ in a certain year, an amount of $\sum_{i=1}^{n} x_{i}$ minus $¥ 2,000$ is refunded. The third term is the total value of the reciprocal gifts provided by the municipal governments. The first term on the right-hand side represents private consumption. The second term represents the total amount of donation. The budget constraint can be simply rewritten as follows:

$$
Y=x_{0}-\sum_{i=1}^{n} p_{i} x_{i}
$$

where $Y \equiv(1-t) y-2,000$. Given the budget constraint, individuals choose $x_{i}$ to maximize utility. Utility maximization yields the first-order condition for $x_{i}$ as: 


$$
a+p_{i}-c x_{i}(1-b)-c b \sum_{i=1}^{n} x_{i}=0 .
$$

By summing the first-order condition for all $i$, we get:

$$
\sum_{i=1}^{n} x_{i}=\frac{n a+\sum_{i=1}^{n} p_{i}}{c(1-b+b n)}
$$

which demonstrates that the total donation increases with an increase in $p_{i}$. Substituting this into (1), the demand function of $x_{i}$ is:

$$
x_{i}^{*}=\frac{a}{c(1-b+b n)}+\frac{(1-2 b+b n) p_{i}}{c(1-b)(1-b+b n)}-\frac{b \sum_{j \neq i} p_{j}}{c(1-b)(1-b+b n)} .
$$

Municipalities. We assume that the municipal government aims to maximize the net revenue from donations. The net revenue of municipality $i$ is given by $R_{i}=x_{i}^{*}-p_{i} x_{i}^{*}$, which is maximized with respect to $p_{i}$. The first-order condition gives the reaction function as:

$$
p_{i}=\left[\frac{b(n-1)}{2(1-2 b+b n)}+\frac{(1-a)(1-b)}{2(1-2 b+b n)}\right]+\frac{b(n-1)}{2(1-2 b+b n)} \frac{\sum_{j \neq i} p_{j}}{n-1},
$$

where $1-2 b+b n=(1-b)+b(n-1)>0 . \sum_{j \neq i} p_{j} /(n-1)$ denotes the average return rate to donations in rival municipalities, suggesting that the games played by the municipalities are strategic complements. It is obvious that the slope of the reaction function becomes steep as $n$ and $b$ become larger. In (3), the competition among the 1,741 municipalities can be depicted as a scenario where municipality $i$ competes with one rival municipality, which summarized the other municipalities except for oneself.

Solving (3) for $\forall i$, we get the return rate in the non-cooperative Nash equilibrium:

$$
p^{N}=\frac{b(n-1)+(a-1)(1-b)}{2(1-b)+b(n-1)} .
$$

The superscript $N$ denotes the non-cooperative equilibrium. The intensity of competition among municipalities can be measured by the number of municipalities $n$, and by the substitutability of donations among municipalities $b$. It can be deduced from (4) that the return rate for donations is high as $n$ and $b$ are large, $\partial p^{N} / \partial n>0$ and $\partial p^{N} / \partial b>0$.

(4) is used to derive the donation level and net revenue for each municipality as:

$$
\begin{aligned}
x^{N} & =\frac{(a+1)(1-2 b+b n)}{c(1-b+b n)(2-3 b+b n)}, \\
R^{N} & =\frac{(a+1)^{2}(1-b)(1-2 b+b n)}{c(2-3 b+b n)^{2}(1-b+b n)} .
\end{aligned}
$$

\subsection{Cooperative outcome}

Our study aims to quantify the extent of the occurrence of inefficiency in comparison to when the government does not compete for donations. Such a non-competitive scenario can be considered either in terms of the collaboration of municipalities to bring the return rate to zero, or in terms of the central government regulating the return rate. Concerning this, we derive the amount of donation and the net revenue of each municipality when the return rate is zero, that is, $p^{C}=0$ : 


$$
\begin{aligned}
x^{C} & =\frac{a}{c(1-b+b n)}, \\
R^{C} & =\frac{a}{c(1-b+b n)},
\end{aligned}
$$

where the superscript $C$ denotes the cooperative equilibrium. The comparison of non-cooperative and cooperative equilibria using (5)-(8) yields the following result:

$$
\begin{aligned}
\frac{x^{N}}{x^{C}} & =1+\frac{b(n-1)-(1-b)(a-1)}{a(2-3 b+b n)} \\
\frac{R^{N}}{R^{C}} & =1+\frac{[(1-b)(a-1)-b(n-1)][(1-b)(a-1)+b(n-1) a]}{a(2-3 b+b n)^{2}} .
\end{aligned}
$$

The advantage of our simple model is that we can quantitatively compare the equilibrium of a cooperative outcome with that of an outcome characterized by a zero return rate, if we have data on the two parameters representing the preference for donations, $a$ and $b$. It is especially important to obtain data on the parameter $b$ as it represents the degree of substitutability for donations among municipalities, which can be obtained by estimating the slope of the reaction curve as depicted in (3).

\section{Empirical analysis}

\subsection{Specification}

Upon testing the theory presented in Section 3, we follow the specification pursued in a large body of empirical studies that test tax competition theory. ${ }^{4}$ Specifically, $p_{i}$ is regressed by $p_{j}$ as shown in (3). However, it is well-known in tax competition literature that an endogeneity problem is encountered in the estimation, since $p_{i}$ and $p_{j}$ are simultaneously determined, and that the estimates are neither unbiased nor consistent with a simple OLS regression. To avoid this, our estimation basically follows the generalized spatial-two stage least squares (GS2SLS) estimation procedure proposed by Kelejian and Prucha (1998), since it is a method that can address both the issues of endogeneity and spatial autocorrelation. ${ }^{5}$ However, GS2SLS is a method developed specifically for cross-sectional analysis. Therefore, our estimation method is specifically based on a spatial random effect panel model, which extends the scope of GS2SLS to panel data analysis by including a spatial lag term and a spatial error term (Mudit et al., 2007; Mutl and Pfaffermayr, 2011).

More specifically, the equations of the estimation are:

$$
\begin{aligned}
& p_{i t}=\beta \sum_{j \neq i} w_{i j} p_{j t}+\sum_{k} b_{k} X_{i t}^{k}+\delta_{t}+u_{i t}, \\
& u_{i t}=\rho \sum_{j \neq i} w_{i j} u_{j t}+\epsilon_{i t}, \text { where } \epsilon_{i t}=\mu_{i}+\nu_{i t} .
\end{aligned}
$$

\footnotetext{
${ }^{4}$ See Brueckner (2003) and Devereux and Loretz (2013) for a review on the empirics of tax competition.

${ }^{5}$ In the case of this estimation, the maximum likelihood method may be sometimes applied. However, it was not adopted in this study, as it requires additional assumptions about the distribution of error terms, and has the disadvantage of calculated load.
} 
Table 3: Descriptive statistics

\begin{tabular}{llrrrr}
\hline & Variables & Mean & Std. Dev. & Min & Max \\
\hline \hline Return rate of own municipality & $p_{i}$ & 0.281 & 0.175 & 0.000 & 3.065 \\
Return rate of other municipalities & $p_{j}$ & 0.275 & 0.110 & 0.000 & 1.482 \\
Population (log) & POP & 10.082 & 1.499 & 5.075 & 15.134 \\
Real debt service ratio & DEBT & 7.470 & 4.488 & -6.400 & 76.800 \\
Taxable income per capita (log) & INCOME & 7.939 & 0.157 & 7.586 & 9.319 \\
Dependency ratio on LAT grant & LAT & 0.508 & 0.272 & 0.000 & 0.956 \\
Financial capability indicator & FCI & 0.506 & 0.286 & 0.053 & 2.153 \\
Agricultural income ratio & AGRI & 0.017 & 0.024 & 0.000 & 0.235 \\
Dependency ratio on NGD & NGD & 0.116 & 0.049 & 0.007 & 0.494 \\
Disaster dummy & DISASTER & 0.140 & 0.347 & 0.000 & 1.000 \\
Tokyo 23 wards dummy & TOKYO & 0.013 & 0.114 & 0.000 & 1.000 \\
Population under 15 years old & $15 U N D E R$ & 0.116 & 0.025 & 0.022 & 0.234 \\
Population over 65 years old & $65 O V E R$ & 0.324 & 0.071 & 0.148 & 0.615 \\
Net balance ratio & NBALANCE & 6.287 & 5.598 & -10.800 & 96.700 \\
Ordinary balance ratio & OBALANCE & 89.140 & 6.716 & 42.200 & 128.400 \\
\hline
\end{tabular}

Note: These descriptive statistics have been computed from the full sample of our data for 2016-2017. NGT denotes national government disbursements and LAT denotes local allocation tax grant. The return rate of other municipalities is a weighted average. $D E B T, N B A L A N C E$, and $O B A L A N C E$ are specified in percentages.

Here, $i$ denotes the concerned municipality and $t$ denotes the year. $p_{i t}$ is the rate of return to donations and $X_{i t}^{k}$ denotes the control variable $k$. When we regress $p_{i t}$ in $p_{j t}$ in the spatial error lag model, there may be regional characteristics that cannot be completely absorbed only by the explanatory variables used in the estimation. In this case, the spatial error term, $u_{i t}$ can be correlated between different municipalities, which causes the estimate to be inefficient. (12) is set to avoid this. A specific estimation method for the spatial random effect estimator is outlined in Appendix A.

In $(11), w_{i t}$ is the spatial weights matrix defined by

$$
w_{i j}=\frac{d_{i j}}{\sum_{j} d_{i j}},
$$

where $d_{i j}$ is a dummy variable, which takes a value of 1 , if municipalities $i$ and $j$ share a boundary and 0 otherwise. There are several ways to define the spatial weight $w_{i j}$, to reflect the spatial influence of municipality $i$ on $j$. The first standard approach is based on the distances between municipalities. The advantage of this approach is easy computation. Typically, the intergovernmental competition for donations closely resembles the degree of competition among neighboring municipalities, however. In such cases, the boundaries shared between municipalities play an important role in determining the degree of spatial influences. The simplest way to capture how close the municipalities are is indicated by whether such spatial units share a boundary, an aspect employed in our study.

\subsection{Descriptive statistics}

The key variable in our estimation of (3) is the return rate for donations, $p_{i t}$, which is calculated as the ratio of gift procurement costs to the donations received by municipality $i$ in year $t$. The followings are the control variables considered: $P O P$ denotes the population and DEBT is the real debt-service ratio, an index to assess the financial burden of debt service expenditure, and is hence used as a criterion to permit the raising of local loans. INCOME is the Logarithmic taxable income per capita. $L A T$ is the ratio of local-allocation-tax grant receipt to revenue resources, which represents how much a municipality's finance depends on grants from the central 
government. LAT grant has no limitations regarding usage. FCI is the financial capability indicator, which indicates the financial strength of municipalities. It is calculated as a threeyear average of past values derived from dividing basic financial revenues by basic financial needs. A higher value indicates that the municipality has a greater margin for revenue sources. $A G R I$ depicts the ratio of primary industry, such as agriculture and fisheries. It is measured by the ratio of agriculture workers to taxpayers. $N G D$ is the ratio of national government disbursements to the total expenditure, which is provided to municipalities to either promote specific policies or for financial aid. DISASTER is a dummy variable which takes a value of 1 if the municipalities are designated as a specific stricken area under the Disaster Relief Act, after having suffered an earthquake. TOKYO is also a dummy variable which takes a value of 1 for Tokyo's 23 special wards. $15 U N D E R$ and $65 O V E R$ are the ratios of the population under 15 years of age and 65 years of age and over, respectively. NBALANCE and OBALANCE are the net fiscal balance and ordinary fiscal balance ratios in each municipality. Finally, we use the year dummy denoted by $Y E A R$.

Table 3 reports the descriptive statistics computed for the full sample. ${ }^{6}$ The variable which we focus on is the return rate on donations. The simple average of the return rate for donations was $27.4 \%$ for 2016 and $29.0 \%$ for 2017 , respectively. However, there was a non-negligible number of municipalities that did not send gifts in return for donations - these are municipalities with a return rate of zero. In 2016, 127 municipalities did not send gifts in return for donations and that number declined to 98 in 2017. Such municipalities constitute $7.3 \%$ and $5.0 \%$ of all municipalities. Since donations to these municipalities are either zero or negligible, it may be interpreted that such municipalities with zero return rates do not compete for donations. Therefore, when the return rate is weighted by the share of the donation in each municipality to the total donation amount in order to account for municipalities with zero return rates, the weighted average of return rates in 2016 and 2017 will be $38.7 \%$ and $38.8 \%$, respectively. That is, the return rate for donations will be close to $40 \%$, if the calculation of return rates is limited to those municipalities that compete for donations by sending gifts.

\subsection{Estimation results}

Estimates. In our study, we utilize a random effects model for the estimation. This is mainly because a large number of variables that represent the characteristics of municipalities are included as explanatory variables. Such variables are characterized by a lower degree of fluctuations yearon-year. This tendency is particularly remarkable, since our sample period is short with only two years of data. In general, a fixed effect model is estimated under the assumption that there is sufficient short-term variation in the data. However, critical information may be lost during estimation with only two years of data available, thereby implying less fluctuation. For instance, Barro (1998) criticizes fixed-effects panel data methods that rely purely on time series information, since conditioning variables often vary gradually over time, such that critical information is lost. In fact, the coefficient representing the slope of the reaction function estimated by a fixed effects model did not produce meaningful estimation results in our estimation. One of the reasons is that there is the issue of missing information specific to fixed effects models. Therefore, following Baltagi et al. (2013), we use the random effects model, which has the advantage of a relatively lower degree of information loss.

The baseline estimates are depicted in Table 4. Of particular interest is the estimates of $p_{j}$, specified in the second row, which suggest that the slope of the reaction function is between 0.373 and 0.412 . This implies that if rival municipalities raise the return rate by $10 \%$ points on an average, the municipality raises it by 3.73 to $4.12 \%$ points. However, this estimation result

\footnotetext{
${ }^{6}$ See Appendix B for the data sources.
} 
Table 4: Estimation results: Baseline

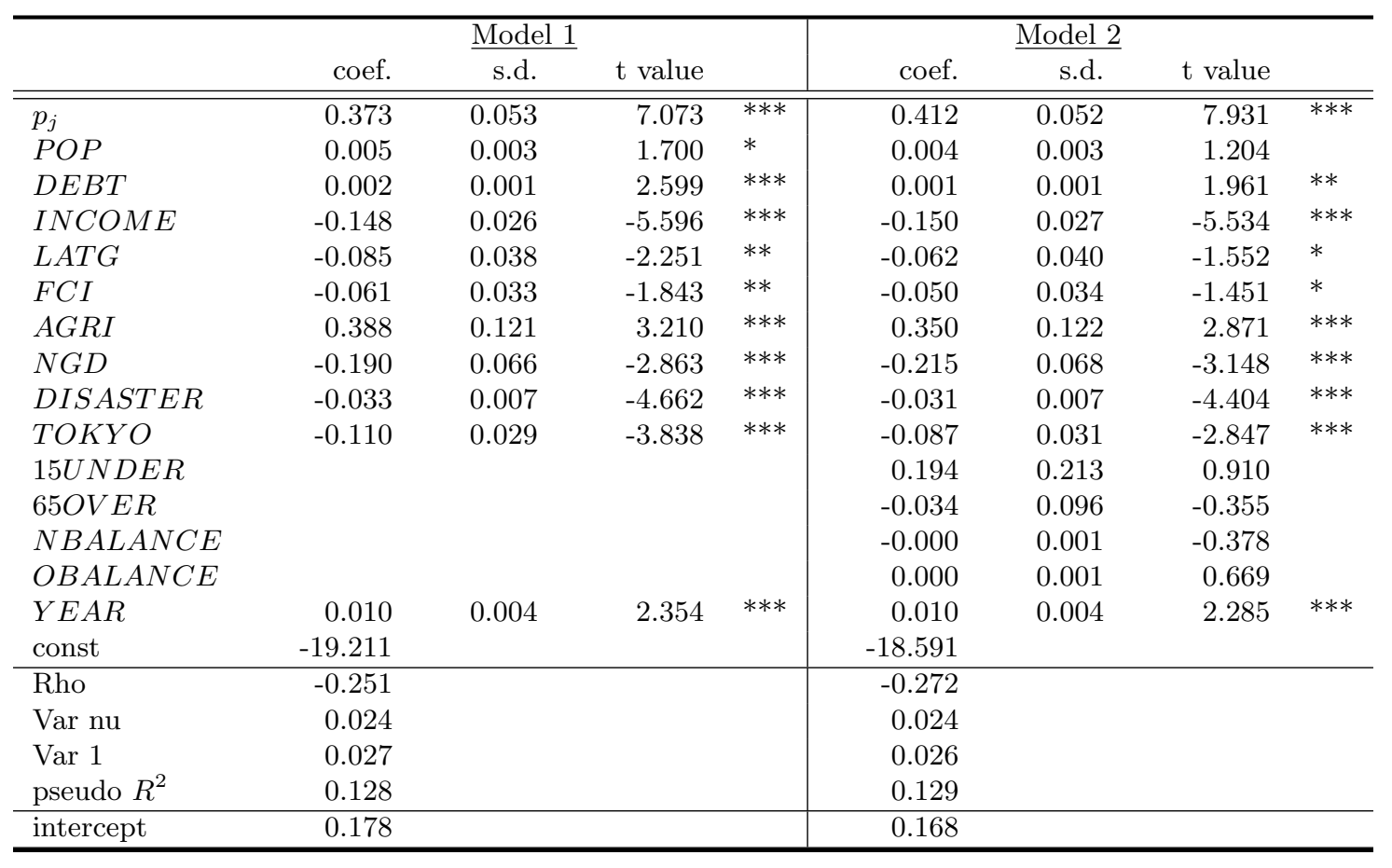

Note. Obs., 3,482. ${ }^{* * *},{ }^{* *}$, and ${ }^{*}$ denote significance at the $1 \%, 5 \%$, and $10 \%$ levels, respectively.

will have too much bias to be deemed reliable, since the model does not fully account for those municipalities with zero return rates. As explained in Section 4.2, upon comparing the simple average with the weighted average, there is a difference of $10 \%$ points or more in the return rate, so it is necessary to control for those municipalities with zero return rates. In addition, there were some municipalities that were considered outliers, with the return rate exceeding $300 \%$. To deal with these municipalities, we introduce two dummy variables. First, we include an outlier dummy to account for municipalities with return rates exceeding $100 \%$. There were five such municipalities in the two years of data for 2016 and 2017. Second, we add a dummy variable, which takes the value 1 for municipalities with zero return rates.

The results estimated based on these treatments are depicted in Table 5, where OUT and $Z E R O$ are dummy variables that represent municipalities with return rates of above $100 \%$ and municipalities with zero return rates, respectively. The estimated values for $p_{j}$ when adding new dummy variables range from 0.247 to 0.267 , suggesting that a $10 \%$-point increase in the return rate raises the return rates of other municipalities by $2.47 \%$ to $2.67 \%$. Since the pseudo $R^{2}$ increased from approximately 0.13 in Table 4 to approximately 0.45 in Table 5 , the estimation results in consideration of the presence of the outlier municipalities and municipalities with a zero return rate improve significantly.

The results of cases where only one of OUT and ZERO is considered are depicted as Models 5 to 8 in Table 8 of Appendix C. In all of these cases, it can be confirmed that the estimates of $p_{j}$ assume values that range between the results of Table 4 and Table 5 .

Quantification. From the estimation results in Tables 4, 5, and 8, the slopes of the reaction functions obtained across eight different models of estimation are in the range of 0.247 to 0.412 . In addition, by using the estimates of the control variables, we can calculate the values of $y$ intercepts of (3). As depicted in the last line of each table, this value ranges between 0.168 and 
Table 5: Estimation results: With $O U T$ and $Z E R O$ dummy variables

\begin{tabular}{|c|c|c|c|c|c|c|c|c|}
\hline & \multicolumn{3}{|c|}{ Model 3} & & \multicolumn{3}{|c|}{ Model 4} & \\
\hline & coef. & s.d. & $\mathrm{t}$ value & & coef. & s.d. & $\mathrm{t}$ value & \\
\hline$p_{j}$ & 0.247 & 0.031 & 8.010 & $* * *$ & 0.267 & 0.031 & 8.706 & $* * *$ \\
\hline$P O P$ & 0.001 & 0.002 & 0.557 & & 0.001 & 0.003 & 0.335 & \\
\hline$D E B T$ & 0.001 & 0.001 & 1.640 & & 0.001 & 0.001 & 1.305 & \\
\hline$I N C O M E$ & -0.104 & 0.021 & -4.994 & $* * *$ & -0.110 & 0.021 & -5.127 & $* * *$ \\
\hline$L A T G$ & 0.009 & 0.031 & 0.279 & & 0.030 & 0.032 & 0.919 & \\
\hline$F C I$ & 0.035 & 0.027 & 1.287 & & 0.040 & 0.028 & 1.420 & \\
\hline$A G R I$ & 0.355 & 0.099 & 3.582 & $* * *$ & 0.300 & 0.101 & 2.984 & $* * *$ \\
\hline$N G D$ & -0.150 & 0.053 & -2.284 & $* * *$ & -0.175 & 0.055 & -3.183 & $* * *$ \\
\hline DISASTER & -0.039 & 0.006 & -6.684 & $* * *$ & -0.038 & 0.006 & -6.305 & $* * *$ \\
\hline TOKYO & 0.016 & 0.024 & 0.659 & & 0.032 & 0.026 & 1.226 & \\
\hline $15 U N D E R$ & & & & & 0.279 & 0.177 & 1.576 & \\
\hline $65 O V E R$ & & & & & -0.030 & 0.080 & -0.375 & \\
\hline$N B A L A N C E$ & & & & & -0.000 & 0.000 & -0.962 & \\
\hline$O B A L A N C E$ & & & & & -0.000 & 0.000 & 0.269 & \\
\hline$O U T$ & 2.093 & 0.057 & 36.504 & $* * *$ & 2.094 & 0.057 & 36.598 & $* * *$ \\
\hline$Z E R O$ & -0.261 & 0.010 & -27.213 & $* * *$ & -0.261 & 0.010 & -27.225 & $* * *$ \\
\hline$Y E A R$ & 0.010 & 0.004 & 2.616 & $* * *$ & 0.010 & 0.004 & 2.744 & $* * *$ \\
\hline const & -18.800 & & & & -19.767 & & & \\
\hline Rho & -0.516 & & & & -0.169 & & & \\
\hline Var nu & 0.016 & & & & 0.016 & & & \\
\hline $\operatorname{Var} 1$ & 0.017 & & & & 0.017 & & & \\
\hline pseudo $R^{2}$ & 0.448 & & & & 0.451 & & & \\
\hline intercept & 0.213 & & & & 0.207 & & & \\
\hline
\end{tabular}

Note. Obs., 3,482. ${ }^{* * *},{ }^{* *}$, and ${ }^{*}$ denote significance at the $1 \%, 5 \%$, and $10 \%$ levels, respectively.

0.213, across eight different models of estimation. Utilizing this information, we can estimate the two preference parameters, $a$ and $b$, and can thus obtain the predicted return rate for the Nash equilibrium. Table 6 shows the estimated return rate in the row written $p^{N}$.

Of course, since Models 1 and 2 utilize estimates that do not adequately control for outlier municipalities and those municipalities with a zero return rate, it is reasonable that predicted return rates are not close to the actual values of return rate. As mentioned in Section 4.2, the weighted average return rate was $38.7 \%$. Since models 3 and 4 control for outliers and municipalities with zero return rates by utilizing two dummy variables, they are able to produce predicted values that are close to the actual weighted average. This implies that the preference parameters $a$ and $b$, determined from the estimated values in Models 3 and 4 , are rather consistent with the observed return rates. Upon inserting the estimates of $a$ and $b$ into (7) and (8), we obtain the amount of donation and net revenue in the counterfactual scenario in which municipalities do not compete for donations by providing reciprocal gifts, and therefore set the return rate to zero. Using these values, the two rows from the bottom of Table 6 depict the difference between the Nash equilibrium and the cooperative outcome for each donation and net revenue.

Models 3 and 4 that best replicate the weighted average value for the actual return rate depict that the provision of "reciprocal" gifts to attract donations leads to an increase in the donation across municipalities in the range of $22.5 \%$ to $24.9 \%$, in comparison to the case where municipalities do not send gifts. On the one hand, this contributes to an increase in the revenue of the municipality. On the other hand, the cost of procuring gifts is high since the estimated return rate to donations is at a high level of $37.3 \%$ to $44.6 \%$. This implies a decline in net revenue. The last row of Models 3 and 4 in Table 6 shows that the net revenue is $10.4 \%$ to $12.1 \%$ lower when the municipalities compete in sending "reciprocal" gift than in the absence 
Table 6: Nash equilibrium and cooperative outcome

\begin{tabular}{|c|c|c|c|c|c|c|c|c|}
\hline Slope & $\begin{array}{c}\text { Model } 1 \\
0.373 \\
\end{array}$ & $\begin{array}{c}\text { Model } 2 \\
0.412 \\
\end{array}$ & $\begin{array}{c}\text { Model } 3 \\
0.247 \\
\end{array}$ & $\begin{array}{c}\text { Model } 4 \\
0.267 \\
\end{array}$ & $\begin{array}{c}\text { Model } 5 \\
0.307 \\
\end{array}$ & $\begin{array}{c}\text { Model } 6 \\
0.332 \\
\end{array}$ & $\begin{array}{c}\text { Model } 7 \\
0.267 \\
\end{array}$ & $\begin{array}{c}\text { Model } 8 \\
0.295 \\
\end{array}$ \\
\hline$a$ & 2.535 & 3.773 & 1.134 & 1.258 & 1.575 & 1.708 & 1.258 & 1.463 \\
\hline$b$ & 0.746 & 0.824 & 0.494 & 0.534 & 0.614 & 0.664 & 0.534 & 0.590 \\
\hline$p^{N}$ & 0.906 & 1.116 & 0.373 & 0.446 & 0.603 & 0.675 & 0.446 & 0.553 \\
\hline$x^{N} / x^{C}$ & 1.112 & 1.076 & 1.249 & 1.225 & 1.180 & 1.187 & 1.225 & 1.194 \\
\hline$R^{N} / R^{C}$ & 0.796 & 0.768 & 0.896 & 0.879 & 0.846 & 0.808 & 0.879 & 0.855 \\
\hline
\end{tabular}

Note. $p^{N}$ is the estimated rate of return. $x^{N}$ and $R^{N}$ are the donations received and the net revenue in each municipality, when the return rate is $p^{N} \cdot x^{C}$ and $R^{C}$ are the donations received and the net revenue in each municipality, when the return rate is zero.

of competition. A similar trend is seen for results based on Models 5 to 8 , where coordinated reduction of return rates from the Nash equilibrium levels toward zero will increase the net revenue of each municipality. This supports the regulation in which the central government sets an upper limit on return rates.

\section{Conclusion}

The current study is the first to estimate the loss from intergovernmental competition for donations under Japan's unique donation system known as the Furusato Nozei (Tax payment to hometown) program. As mentioned in the introduction, this program is controversial regarding its merits and demerits. One main criticism was that it allows individuals to choose which municipality they pay their taxes to. This deviates from the principles of local taxation that stipulates the payment of tax for receiving local public services. The program's pros and cons have further been clearly identified (Sato, 2017). Among the several issues, excessive return gifts competition has become so serious that the central government was forced to introduce new regulations involving legal reform. However, the basis for the regulation is weak, since we see no quantitative explanation so far. To study the extent of excess intergovernmental competition, we develop a model for interregional municipal competition for donations and estimate the degree of response by municipalities to the policies of others. We then used estimates to quantify the loss of net revenue caused by intergovernmental competition in the program.

The quantitative results obtained by this study are as follows.

Firstly, there is evidence of competition between municipalities. Specifically, when rival municipalities raise the return rate for donations by $10 \%$ points, the concerned municipality, in turn, raises it from $2.5 \%$ to $4.1 \%$ points. In the best case scenario that involves reproducing the actual weighted averages, these are 2.5 to $2.7 \%$ points. Secondly, based on the model that best reproduces the observation, the competition among municipalities increases donations by $22.5 \%$ to $24.9 \%$, in comparison to a hypothetical scenario with no competition in return rates. Third, since a municipality competes to attract donations by raising return rates, the cost of procuring gifts for the collected donations increases. As a result, the net revenue is smaller than without competition in return rates. Specifically, our estimation depicts that due to intergovernmental competition through increasing return rates for donations, the net revenue will decline by $10.4 \%$ 
to $12.1 \%$ in comparison to a scenario without competition. This suggests that the municipality has provided an excessive amount of "reciprocal" gifts, thereby leading to an excessive cost of gift procurement, in terms of the ability of municipalities in securing a larger net revenue.

In conclusion, we list three issues left unaddressed in this study. First, since we utilized samples where the number of municipalities with a zero return rate accounted for $5-7 \%$ of the total, we use dummy variables to account for such municipalities. An alternative approach is to use other methods such as spatial autoregressive Tobit model, which may be useful to verify the robustness of the results. Second, we used a spatial weight matrix based on whether municipalities share the boundaries. However, given that the individuals decide where to donate on the web, it would be useful to develop a new indicator that shows the proximity of municipalities in electronic space. Third, we set the outcome with zero return rates as a comparison target in the attainment of Nash equilibrium. In other words, we clarified the extent of the reduction in net revenue that intergovernmental competition brings, in comparison to the case where municipalities do not compete for donations using reciprocal gifts. Other cases that can be compared concerns the cooperation in setting the return rate so as to maximize their total net revenue. In this case, it is expected that the return rate will be negative, implying that taxing donations results in maximizing the total net revenue. This is not a realistic scenario under the framework of the Furusato Nozei program in practice, however. Still, there is room to discuss the formulation of a cooperative (or optimal) solution under this unique donation program.

Acknowledgment. The third author acknowledges the financial support of JSPS Grant nos. $16 \mathrm{~K} 12374$ and $19 \mathrm{H} 01505$.

\section{Appendices}

Appendix A. Here, we explain the estimation method of spatial random effect estimator. The spatial random effect estimator we estimated is based on Mutl and Pfaffermayr (2011). Using matrix notation, the model for a single period $t$ can be rewritten as

$$
\begin{aligned}
\mathbf{y}_{t, N} & =\lambda \mathbf{W}_{N} \mathbf{y}_{t, N}+\mathbf{X}_{t, N} \boldsymbol{\beta}+\alpha \iota_{N}+\mathbf{u}_{t, N}, \\
\mathbf{u}_{t, N} & =\rho \mathbf{W}_{N} \mathbf{u}_{t, N}+\varepsilon_{t, N}, \\
\varepsilon_{t, N} & =\boldsymbol{\mu}_{N}+\boldsymbol{\nu}_{t, N}, \\
E\left(\mu_{N}\right) & =0, E\left(\mu_{N^{2}}\right)=\sigma_{\mu}^{2}, \\
E\left(\nu_{t, N}\right) & =0, E\left(\nu_{t, N}^{2}\right)=\sigma_{\nu}^{2},
\end{aligned}
$$

where

$$
\begin{aligned}
& \mathbf{y}_{t, N}=\left(\begin{array}{c}
y_{t 1, N} \\
\vdots \\
y_{t N, N}
\end{array}\right), \quad \mathbf{X}_{t, N}=\left(\begin{array}{c}
\mathbf{x}_{t 1, N} \\
\vdots \\
\mathbf{x}_{t N, N}
\end{array}\right), \quad \mathbf{u}_{t, N}=\left(\begin{array}{c}
u_{t 1, N} \\
\vdots \\
u_{t N, N}
\end{array}\right), \\
& \varepsilon_{t, N}=\left(\begin{array}{c}
\varepsilon_{t 1, N} \\
\vdots \\
\varepsilon_{t N, N}
\end{array}\right), \quad \nu_{t, N}=\left(\begin{array}{c}
\nu_{t, N} \\
\vdots \\
\nu_{t N, N}
\end{array}\right), \quad \mu_{N}=\left(\begin{array}{c}
\mu_{1, N} \\
\vdots \\
\mu_{N, N}
\end{array}\right), \\
& \mathbf{W}_{N}=\left(\begin{array}{ccc}
w_{11, N} & \cdots & w_{1 N, N} \\
\vdots & \ddots & \vdots \\
w_{N 1, N} & \cdots & w_{N N, N}
\end{array}\right) .
\end{aligned}
$$


We estimate the parameters in three steps:

Step1 (2SLS estimation). We estimated the parameters of (13) using 2SLS and obtained the residuals. Here, we used $W_{N} X_{t, N}$ (the average of adjacent municipalities' explanatory variables) as instruments.

Step 2 (Estimation of non-linear parameters). For convenience, we use the notation $\sigma_{1}^{2}=T \sigma_{\mu}^{2}+\sigma_{\nu}^{2}$ and define the matrices

$$
\begin{aligned}
\mathbf{Q}_{0, N} & =\left(\mathrm{I}_{T}-\frac{1}{T} \mathbf{J}_{T}\right) \otimes \mathrm{I}_{N}, \\
\mathbf{Q}_{1, N} & =\frac{1}{T} \mathrm{~J}_{T} \otimes \mathrm{I}_{N},
\end{aligned}
$$

where $\mathrm{J}_{T}$ is a $T \times T$ matrix of unit elements.

First, using the residuals $u$ in Step 1, we estimated the parameters $\rho$ and $\sigma_{\nu}$ based on the three moment conditions given in Kapoor et al. (2007):

$E\left[\begin{array}{c}\frac{1}{N(T-1)} \mathbf{u}_{N}^{\prime} \mathbf{Q}_{0, N}\left(\mathbf{I}_{N T}-\rho \mathrm{W}_{N T}^{\prime}\right)\left(\mathbf{I}_{N T}-\rho \mathrm{W}_{N T}\right) \mathbf{Q}_{0, N} \mathbf{u}_{N} \\ \frac{1}{N(T-1)} \mathbf{u}_{N}^{\prime} \mathbf{Q}_{0, N}\left(\mathbf{I}_{N T}-\rho \mathrm{W}_{N T}^{\prime}\right) \mathbf{M}_{N}^{\prime} \mathbf{M}_{N}\left(\mathbf{I}_{N T}-\rho \mathrm{W}_{N T}\right) \mathbf{Q}_{0, N} \mathbf{u}_{N} \\ \frac{1}{N(T-1)} \mathbf{u}_{N}^{\prime} \mathbf{Q}_{0, N}\left(\mathbf{I}_{N T}-\rho \mathrm{W}_{N T}^{\prime}\right) \mathbf{M}_{N}^{\prime}\left(\mathbf{I}_{N T}-\rho \mathrm{W}_{N T}\right) \mathbf{Q}_{0, N} \mathbf{u}_{N}\end{array}\right]=\left[\begin{array}{c}\sigma_{\nu}^{2} \\ \sigma_{\nu}^{2} \frac{1}{N} \operatorname{tr}\left(\mathrm{W}_{N T}^{\prime} \mathrm{W}_{N T}\right) \\ 0,\end{array}\right]$,

where $\mathrm{W}_{N T}=\left(\mathbf{I}_{T} \otimes \mathbf{W}_{N}\right)$.

Next, using the estimated parameters $\rho$ and $\sigma_{\nu}$, we calculated the parameter $\sigma_{1}$ based on the moment condition

$$
E\left[\frac{1}{N} \mathbf{u}_{N}^{\prime} \mathbf{Q}_{1, N}\left(\mathbf{I}_{N T}-\rho \mathrm{W}_{N T}^{\prime}\right)\left(\mathbf{I}_{N T}-\rho \mathrm{W}_{N T}\right) \mathbf{Q}_{1, N} \mathbf{u}_{N}\right]=\sigma_{1}^{2}
$$

Step 3 (Estimation of linear parameters). Using the estimated parameters in Step 2, spatial random effect estimator $\widehat{\boldsymbol{\delta}}_{G L S, N}=\left(\widehat{\boldsymbol{\theta}}_{G L S, N}, \widehat{\alpha}_{G L S, N}\right)^{\prime}=\left(\lambda, \boldsymbol{\beta}^{\prime}, \alpha\right)^{\prime}$ is given by

$$
\widehat{\boldsymbol{\delta}}_{G L S, N}=\left[\widehat{\widetilde{\mathbf{Z}}}_{N}^{\prime}(\boldsymbol{\vartheta})^{\prime} \widetilde{\mathbf{Z}}_{N}(\boldsymbol{\vartheta})\right]^{-1} \widehat{\widetilde{\mathbf{Z}}}_{N}^{\prime}(\boldsymbol{\vartheta}) \widetilde{\mathbf{y}}_{N}(\boldsymbol{\vartheta})
$$

with $\widehat{\widetilde{\mathbf{Z}}}_{N}(\boldsymbol{\vartheta})=\mathbf{P}_{H_{R, N}} \tilde{\mathbf{Z}}_{N}(\boldsymbol{\vartheta}), \widetilde{\mathbf{Z}}_{N}(\boldsymbol{\vartheta})=\boldsymbol{\Omega}_{u, N}^{-1 / 2}(\boldsymbol{\vartheta}) \mathbf{Z}_{N}, \widetilde{\mathbf{y}}_{N}(\boldsymbol{\vartheta})=\boldsymbol{\Omega}_{u, N}^{-1 / 2}(\boldsymbol{\vartheta}) \mathbf{y}_{N}$ and $\boldsymbol{\Omega}_{u, N}^{-1 / 2}=$ $\left(\mathbf{Q}_{0, N}+\frac{\sigma_{\nu}}{\sigma_{1}} \mathbf{Q}_{1, N}\right)\left(\mathbf{I}_{N T}-\rho \mathrm{W}_{N}\right)$. Here, $\mathbf{P}_{H_{R, N}}=\mathbf{H}_{R, N}\left(\mathbf{H}_{R, N}^{\prime} \mathbf{H}_{R, N}\right)^{-1} \mathbf{H}_{R, N}^{\prime}$ is the projection matrix based on the instruments $\mathbf{H}_{R, N}=\left[H_{Q, N}, H_{P, N}\right]=\left[\mathbf{Q}_{0, N}\left[X_{N}, W_{N} X_{N}\right], \mathbf{Q}_{1, N}\left[X_{N}, W_{N} X_{N}, \iota_{N T}\right]\right]$.

Mutl and Pfaffermayr (2011) have proven that

$$
\sqrt{N T}\left(\theta_{G L S, N}-\theta\right) \stackrel{d}{\rightarrow} N\left(0, \Sigma_{G L S}\right)
$$

where $\Sigma_{G L S}$ is the upper-left $(K+1) \times(K+1)$ block of the matrix $\sigma_{\nu}^{2}\left(\mathbf{M}_{H_{R} \bar{Z}}^{\prime} \mathbf{M}_{H_{R} H_{R}}^{-1} \mathbf{M}_{H_{R} \bar{Z}}\right)^{-1}$. $K$ denotes the number of explanatory variables in $X_{t, N}$. Then, we constructed the standard errors of the coefficients using these results. 
Table 7: Data Sources

\begin{tabular}{llc}
\hline Variables & Data name & Publisher \\
\hline \hline$p_{i}$ & Findings on Furusato nozei program & MIAC \\
POP & Report on population, demographics and number of households & MIAC \\
DEBT & Financial settlement of municipalities & MIAC \\
INCOME & Taxation settlement of municipalities & MIAC \\
LATG & Financial settlement of municipalities & MIAC \\
$F C I$ & Financial settlement of municipalities & MIAC \\
$A G R I$ & Taxation settlement of municipalities & MIAC \\
NGD & Taxation settlement of municipalities & MIAC \\
$D I S A S T E R$ & List of areas affected by the disaster & JPO \\
TOKYO & - & - \\
$15 U N D E R$ & Report on population, demographics and number of households & MIAC \\
$65 O V E R$ & Report on population, demographics and number of households & MIAC \\
NBALANCE & Financial settlement of municipalities & MIAC \\
OBALANCE & Financial settlement of municipalities & MIAC \\
\hline
\end{tabular}

Note. MIAC: Ministry of Internal Affairs and Communications; JPO: Japan Patent Office.

Appendix B. The data sources are in Table 7.

Appendix C. Table 8 shows the estimation results when only one of $O U T$ and $Z E R O$ is a dummy variable. 


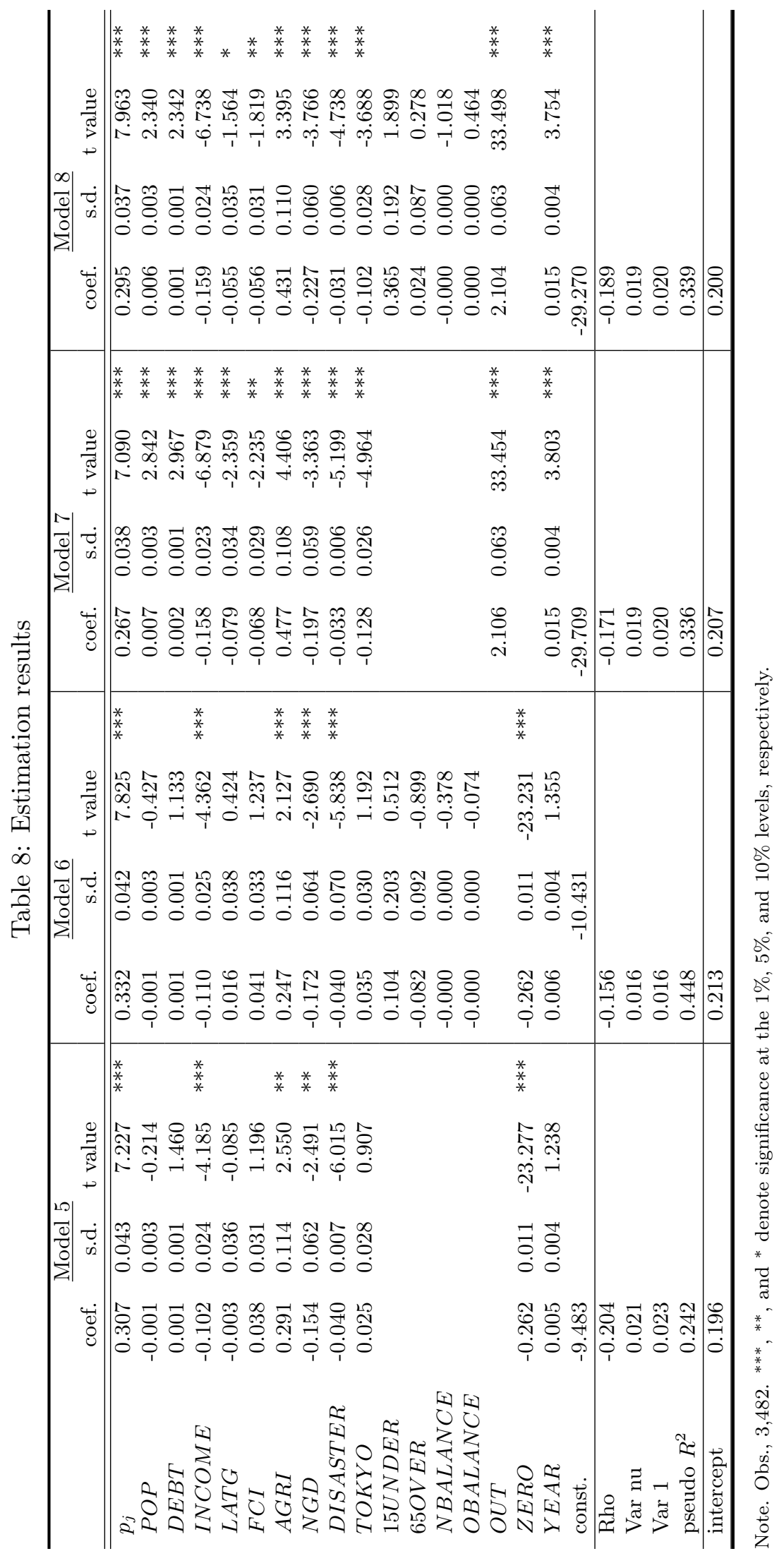




\section{References}

Baltagi, B.H., Fingleton, B. \& Pirotte, A. (2014), Spatial lag models with nested random effects: An instrumental variable procedure with an application to English house prices, Journal of Urban Economics, 80, 76-86.

Barro, R. (1998), Determinants of economic growth: a cross-country empirical study, Cambridge, MA: The MIT Press.

Bessho, S. (2017), How should the regional fiscal disparities be corrected? (in Japanese), Chuo Koron, 131(3), 76-83.

Brueckner, J.K. (2003). Strategic interaction among governments: An overview of empirical studies, International Regional Science Review, 26, 175-188.

Devereux, M., \& Loretz, S. (2013). What do we know about corporate tax competition? National Tax Journal, 66, 745-774.

Fukasawa, E. (2019), The essence of phenomena caused by the Homeland Tax donation system in Japan (in Japanese), The Reference, no.818, 53-79.

Hashimoto, K., \& Suzuki, Y. (2016), The Hometown Tax Payment system: Current trends and issues (in Japanese), Kaikei Kensa Kenkyu, 54, 13-38.

Hausman, J.A. (1978). Specification tests in econometrics, Econometrica, 46, 1251-1271.

Japan Times (2017), Hometown tax donation system (March 11, 2017), https://www . japantimes . co.jp/opinion/2017/03/11/editorials/review-of-the/\#.XN_7HMj7Q2w.

Kapoor, M., Kelejian, H.H., \& Prucha, I.R. (2007). Panel data models with spatially correlated error components, Journal of Econometrics, 140, 97-130.

Kelejian, H.H., \& Prucha, I.R. (1998). A generalized spatial two-stage least squares procedure for estimating a spatial autoregressive model with autoregressive disturbances, Journal of Real Estate Finance and Economics, 17, 99-121.

Mudit, K., Kelejian, K., \& Prucha, I. (2007), Panel data models with spatially correlated error components, Journal of Econometrics, 140, 97-130.

Mutl, J., \& Pfaffermayr, M. (2011), The Hausman test in a Cliff and Ord panel model, The Econometrics Journal, 14, 48-76.

Nishimura, Y., Ishimura, T., \& Akai, N. (2017), Analysis on incentives of hometown tax payment: Empirical analysis using donation acceptance data of municipalities (in Japanese), in Japan Association of Local Public Finance eds., "Regional revitalization" and the role of local governments', Keiso-shobo, Tokyo,

Rausch, A. (2017), A paradox of Japanese taxation: Analyzing the Furusato Nozei tax system, The Asia-Pacific Journal, 15(11,6), 1-18.

Sato, M. (2017), Pros and cons of the "Hometown Tax" donation program: Return gifts should be excluded from deductibles (in Japanese), Nikkei News Paper, April 7, 2017. Translated into English at https://www.rieti.go.jp/en/papers/contribution/sato-motohiro/ $02 . \mathrm{html}$. 
Suzuki, Y., \& Hashimoto, K. (2017), Study on Furusato Nozei: The case of municipalities in Hokkaido (in Japanese), Ikoma Keizai Ronso, 15, 21-31.

Wilson, J.D. (1986), A theory of interregional tax competition, Journal of Urban Economics, 19, 296-315.

Wildasin, D.E. (1988), Nash equilibria in models of fiscal competition, Journal of Public Economics, 35, 229-240.

Yamamura, E., Tsutsui, Y., \& Ohtake, F. (2018). Altruistic and selfish motivations of charitable giving: The case of the hometown tax donation system (Furusato nozei) in Japan, MPRA paper 86181.

Zodrow, G.R. \& Mieszkowski, P. (1986), Pigou, Tiebout, property taxation, and the underprovision of local public goods, Journal of Urban Economics, 19, 356-370. 